Fetal Diagnosis and Therapy
Fetal Diagn Ther 2012;32:292-294

DOI: $\underline{10.1159 / 000337612}$
Received: January 4, 2012

Accepted after revision: February 13, 2012

Published online: June 1, 2012

\title{
Hepatitis E Virus Infection Causing Isolated Fetal Ascites: A Case Report
}

\author{
Mandakini Pradhan Bhavna Anand Asha Singh \\ Department of Maternal and Reproductive Health, Sanjay Gandhi Post Graduate Institute of Medical Sciences, \\ Lucknow, India
}

\section{Established Facts}

- Isolated fetal ascites is a different entity from fetal hydrops.

- Maternal viral infection like hepatitis A, hepatitis C, cytomegalovirus, enterovirus and parvovirus $\mathrm{B} 19$ have been reported to be associated with isolated fetal ascites.

\section{Novel Insights}

- Maternal hepatitis E virus (HEV) infection can cause isolated fetal ascites.

\section{Key Words}

Hepatitis E · Fetal ascites • Maternal infection

\begin{abstract}
Maternal hepatitis infection, excepting hepatitis $E$, causing isolated fetal ascites with variable outcome has been reported previously. We present a case of maternal hepatitis E virus (HEV) infection causing isolated fetal ascites which resolved spontaneously during pregnancy and resulted in a term liveborn baby with anti-HEV seropositivity. A 39-year-old primigravida woman was diagnosed with acute HEV infection at 15 weeks of gestation. Ultrasound at 19 weeks showed significant fetal ascites with abdominal calcifications. Fetal karyotype did not show any abnormality. Cord blood was positive for anti-HEV IgM and negative for other intrauterine
\end{abstract}

infections. Ultrasound at 25 weeks showed partial resolution of fetal ascites with complete resolution at 30 weeks. She delivered a healthy baby at 38 completed weeks, with normal liver enzymes at birth and 1-month follow-up.

Copyright $\odot 2012$ S. Karger AG, Basel

\section{Case Report}

A 39-year-old primigravida presented at 15 weeks of gestation with hyperbilirubinemia due to hepatitis E infection. Her serum alanine aminotransferase and aspartate aminotransferase were six times the normal value with normal prothrombin time and activated partial thromboplastin time. Her past medical history and family history were non-contributory. She tested negative for HIV (both I and II), syphilis, IgM toxoplasmosis, rubella, cytomegalovirus infection, herpes simplex virus infection and parvovirus B19

\section{KARGER}

Fax +4161306 1234

E-Mail karger@karger.ch

www.karger.com
(C) 2012 S. Karger AG, Basel

$1015-3837 / 12 / 0324-0292 \$ 38.00 / 0$

Accessible online at:

www.karger.com/fdt
Prof. Mandakini Pradhan

Department of Maternal and Reproductive Health

Sanjay Gandhi Post Graduate Institute of Medical Sciences

Lucknow, UP 226014 (India)

Tel. +91 522266 4618, E-Mail mandakini_pradhan@rediffmail.com 


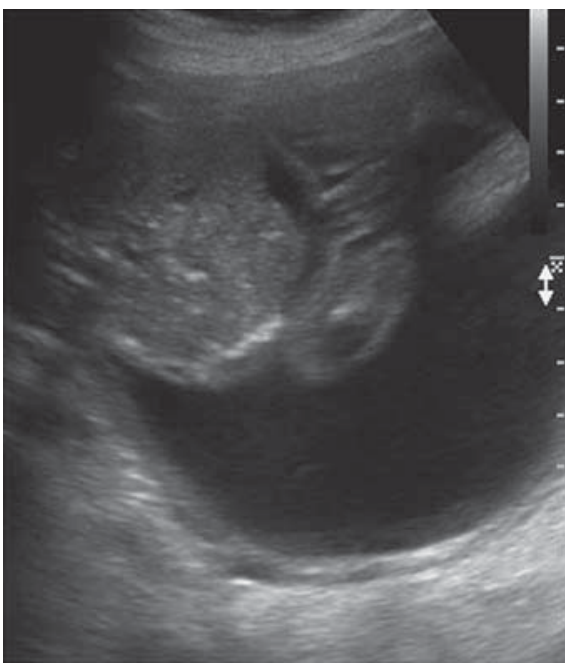

Fig. 1. Fetal ascites from acute infection with hepatitis E.

infection. She was also negative for HBsAg, HAV IgM and antiHCV antibody and positive for HEV IgM. She had her first-trimester ultrasound (US) and double-marker serum screen for fetal aneuploidy at 12 weeks which was at low risk, i.e. less than 1 in 10,000.

Her obstetrical US showed a singleton pregnancy of 19 weeks with fetal ascites with no evidence of fluid accumulation in other serous body cavities (fig. 1). The fetal abdomen showed echogenic bowel. No other major or minor malformation was detected. Placental thickness and the amount of liquid was normal. US was repeated after 2 weeks to confirm the isolated nature of ascites. Her fetal echocardiography was normal. A diagnosis of isolated fetal ascites due to viral hepatitis was made. The cordocentesis done showed normal fetal karyotype. Cord blood was positive for anti-HEV IgM and negative for toxoplasmosis, CMV and parvovirus B19 IgM and also negative for common mutation of cystic fibrosis (p.F508del; c.1161delC; c.3849+10 kb C >T and p.S549N). Amniotic fluid which was collected simultaneously was also positive for anti-HEV. At follow-up, her total billirubin had not increased further and liver enzyme levels gradually decreased and reached a normal level over the subsequent 10 weeks. US at 24 weeks showed partial resolution of fetal ascites with complete resolution at 30 weeks. At 38 weeks she went into spontaneous labor and had a normal delivery of a 2,500-gram female baby with normal liver enzyme levels at birth and 1-month follow-up. At birth, anti-HEV IgM and IgG from cord blood were positive. The mother's postpartum period was uneventful.

\section{Discussion}

The term isolated fetal ascites is defined as the presence of significant fluid in the abdominal cavity in the absence of any detectable malformations or fluid elsewhere. Prenatal diagnosis of a case of isolated fetal ascites should involve a systematic and individualized approach and is possible in up to $92 \%$ of cases [1]. A wide range of etiologies is associated with isolated fetal ascites which includes fetal chromosomal abnormality, malformation, intrauterine infection, genetic disorders, intestinal perforation, neoplasms and growth retardation.

Seven cases of viral infection during pregnancy associated with isolated fetal ascites have been reported which include 2 cases of hepatitis A [2,3], 1 case of hepatitis C [4], 2 cases of CMV [5], 1 case of parvovirus [6], and 1 case of enterovirus [7]. In both reported cases of hepatitis A infection during pregnancy $[2,3]$, at 13 and 20 weeks of gestation, respectively, fetal ascites was noted after 7 weeks of maternal infection and resulted in meconium peritonitis. Both cases required surgical management after delivery.

One case of hepatitis $\mathrm{C}$ infection during pregnancy [4] at 17 weeks of gestation had significant fetal ascites for which paracentesis was done at 23 weeks and the child after delivery was healthy with anti-HCV seropositivity. One case of chronic active hepatitis B infection superimposed with CMV infection during pregnancy at 25 weeks developed meconium peritonitis and died in utero [5].

HEV is a non-enveloped single-stranded RNA virus and is prevalent in Southeast and Central Asia, the Middle East and parts of Africa and Mexico. The infection usually presents in the epidemic form and is transmitted by the fecal-oral route (usually through contaminated water). Although the mortality rate is usually low (0.07$0.6 \%$ ) in non-pregnant women, the infection may have a severe course in pregnancy, especially if the infection is acquired in the late trimester, with mortality rates reaching as high as $25-40 \%$. Little data is available about the fetal effects due to hepatitis $\mathrm{E}$ infection. The complications that are reported in the literature include an increased incidence of preterm delivery [8], the majority of which are iatrogenic and with high perinatal mortality. To the best of our knowledge, fetal ascites from acute infection with hepatitis $\mathrm{E}$ has never been reported and this is the first case to be reported.

\section{Conclusion}

Second-trimester maternal HEV infection can cause transplacental transmission to the fetus and isolated fetal ascites. These cases may have a successful outcome. 


\section{References}

1 Schmider A: Etiology and prognosis of fetal ascites. Fetal Diagn Ther 2003;18:230-236.

$\checkmark 2$ McDuffe RS Jr, Bader T: Fetal meconium peritonitis after maternal hepatitis A. Am J Obstet Gynecol 1999;180:1031-1032.

$>3$ Leikin E, Lysikiewicz A, Garry D, Tejani N: Intrauterine transmission of hepatitis A virus. Obstet Gynecol 1996;88:690-691.
4 Ling PY: Fetal ascites and second-trimester maternal hepatitis $\mathrm{C}$ virus infection. Taiwan J Obstet Gynecol 2006;45:260-263.

5 Nigro G, La Torre R, Mazzocco M, Coacci F, Riosa B, D’Emilio C, Cosmi EV: Multi-system cytomegalovirus fetopathy by recurrent infection in a pregnant woman with hepatitis B. Prenat Diagn 1999;19:1070-1072.

$\checkmark 6$ Macé G, Audry G, Cortey A, Nguyen A, Slaim L, Castaigne V, Garel C, Carbonne B: Congenital hypoplasia of the abdominal wall muscles following fetal ascites due to parvovirus B19 infection. Ultrasound Obstet Gynecol 2011;37:497-498.
7 Chow KC, Lee CC, Lin TY, Shen WC, Wang JH, Peng CT, Lee CC: Congenital enterovirus 71 infection: a case study with virology and immunohistochemistry. Clin Infect Dis 2000;31:509-512.

8 Kumar A: Hepatitis E in pregnancy. Int J Gynecol Obstet 2004;85:240-244. 